\title{
Quality of life following surgery for large and giant vestibular schwannomas: a prospective study
}

\author{
Mazda K. Turel, MCh, Sumit Thakar, MCh, and Vedantam Rajshekhar, MCh \\ Department of Neurological Sciences, Christian Medical College, Vellore, Tamil Nadu, India
}

OBJECT Prospective studies of quality of life (QOL) are infrequently performed in patients undergoing surgery for vestibular schwannoma (VS). The authors designed this to study to investigate health-related QOL (HR-QOL) in patients with large and giant VSs before and after surgery.

METHODS Between January 2009 and December 2012, HR-QOL was measured prospectively before and after surgery, using the 36-Item Short Form Health Survey (SF-36), in 100 patients who underwent surgery for unilateral large or giant VS (tumor size $\geq 3 \mathrm{~cm}$ ). The Glasgow Benefit Inventory (GBI) was also used to evaluate the effect of surgery.

RESULTS A total of 100 patients were included in the study (65 men and 35 women). Their mean age ( \pm SD) was 44.2 \pm 11.5 years. The preoperative QOL was decreased in all SF-36 domains. A 1-year follow-up evaluation was conducted for all patients (mean 13.5 \pm 5.3 months after surgery). The results showed an improvement in HR-QOL compared with preoperative status in all cases, with $63 \%-85 \%$ of patients showing a minimum clinically important difference (MCID) in various domains. A second follow-up evaluation was performed in 51 cases (mean time after surgery, $29.0 \pm 8.3$ months) and showed sustained improvement in SF-36 scores. In some domains there was further improvement beyond the first follow-up. On the $\mathrm{GBI}, 87 \%$ of patients reported improvement, $1 \%$ felt no change, and $12 \%$ of patients reported deterioration.

CONCLUSIONS Patients harboring large or giant VSs score lower on all the QOL domains compared with the normative population. More than $60 \%$ showed a clinically significant improvement in HR-QOL 1 year after surgery, a result that was sustained at subsequent follow-up.

http://thejns.org/doi/abs/10.3171/2014.10.JNS14534

KEY WORDS brain tumor; Glasgow Benefit Inventory; Short-Form 36; quality of life; surgery; oncology

A DISCREPANCY between surgeon-assessed and patient-perceived outcomes of vestibular schwannoma (VS) surgery has been reported..$^{16,19,22}$ Hence, there is a need for greater emphasis on quality of life (QOL) outcomes (which are patient reported) following surgery for VS. Most of the QOL studies in patients undergoing surgery for VS are retrospective and include patients with small tumors. ${ }^{1-7,14,18,21,23,27,28,31}$ Few studies have reported QOL following surgery for large VS, but even those have mostly been retrospective in nature..$^{22,25}$

One of the major deficiencies in QOL studies on VS patients is the lack of a planned prospective comparison between QOL values before and after treatment in large cohorts of patients. ${ }^{10,11}$ The few published prospective studies involved patients with small VSs $(<3 \mathrm{~cm}){ }^{20,24,26}$ To our knowledge there is only one prospective report of QOL in patients with larger tumors $(>3 \mathrm{~cm})$, and that study involved 37 patients. $^{8}$

None of the reports of QOL in patients with VS have included the proportion of patients showing a minimum clinically important difference (MCID) in the different QOL domains. Surgeons need to know whether an observed change in score represents a clinically important improvement or deterioration rather than merely an inconsequential fluctuation. Differences in scores smaller than the MCID are considered unimportant, regardless of whether statistical significance is reached. To date, such information has not been provided in any published report on QOL in VS patients.

We aimed to study the factors affecting QOL in pa-

ABBREVIATIONS CN = cranial nerve; GBI = Glasbow Benefit Inventory; HR-QOL = health-related QOL; MCID = minimum clinically important difference; QOL = quality of life; SEM = standard error of measurement; $S F=36=36$-Item Short Form Health Survey; VS = vestibular schwannoma.

SUBMITTED March 10, 2014. ACCEPTED October 27, 2014.

INCLUDE WHEN CITING Published online December 5, 2014; DOI: 10.3171/2014.10.JNS14534.

DISCLOSURE This study was funded by a Fluid research grant provided by Christian Medical College, Vellore, India. The authors have no personal financial or institutional interest in any of the drugs, materials, or devices described in this article. 
tients with large and giant tumors before and 1 year after surgery, using the 36-Item Short Form Health Survey (SF36) and Glasgow Benefit Inventory (GBI) scales. We also report, for the first time, the proportion of patients showing MCID in the different domains of SF-36.

\section{Methods}

\section{Patient Population}

Between January 2009 and December 2012, 100 consecutive patients who underwent surgery for unilateral VS at a tertiary referral center were prospectively studied. The study was approved by the Christian Medical College institutional review board. Informed consent was obtained from all patients enrolled in the study. Because the questionnaires used in the study were designed to be selfadministered, illiterate patients (5 patients) were excluded. Patients who had bilateral VS (6 patients) or who underwent tumor surgery elsewhere (7 patients) and presented to us with residual/recurrent tumor were excluded. Two patients who presented to us in altered sensorium and were discharged in a good condition were also excluded due to our having been unable to obtain preoperative scores in these cases. One patient discharged in a moribund condition and 2 others who died of operative complications were also excluded from the study.

Facial nerve function was scored by the House-Brackmann classification..$^{12}$ All patients had preoperative MRI, and tumor size was calculated using the single largest diameter in the subarachnoid space. Preoperative clinical and radiological data were entered prospectively into a preliminary form and subsequently into an Excel database (Microsoft Inc.)

\section{Evaluation of Health Status}

Health status was assessed preoperatively and postoperatively using a licensed version of the SF-36 (Quality Metric) that was translated into local Indian languages. The answers of all responders were compared with normative data for the Indian population that we had obtained in a previous study. ${ }^{30}$

The SF-36 is designed as a generic indicator of health status and measures 8 health concepts: physical functioning, physical role, social functioning, emotional role, general health, mental health, bodily pain, and vitality. A subscale score is calculated for each of the 8 dimensions. The physical component summary and mental component summary scores are derived by an algorithm that integrates different scales. The scores obtained using this instrument yield a profile of functional status that constitutes an objective health-related QOL (HR-QOL) assessment. ${ }^{30}$

In addition, at 1-year follow-up the GBI questionnaire was administered. This instrument, too, was generated in local languages through a forward-backward translation with preservation of content after backward translation. ${ }^{1}$ The GBI questionnaire asks the subject to compare QOL before and after a specific event (i.e., surgery for VS).

The questionnaire contains 18 questions with 5 reply alternatives: much better, better, unchanged, worse, and much worse. Twelve questions address general and psychosocial health, 3 reflect social support, and 3 deal with phys- ical health. The responses on the general scale and on the subscales are averaged so that the scores for each one can range between -100 (maximum negative effect) and +100 (maximum positive effect), passing through 0 (no change). In other words, positive results indicate an improvement in QOL and negative ones a worsening, and results equal to 0 indicate the absence of changes in the QOL. ${ }^{1}$

\section{Surgery}

In all cases surgery was performed via the retromastoid suboccipital approach with the patient in the lateral position. Intraoperative facial nerve monitoring was routinely used. We routinely attempted total excision of the tumors (Figs. 1 and 2). A subtotal excision was done to preserve function of cranial nerve (CN) VII (in 10 cases) or due to dense adhesion of the tumor to the cranial nerves or brainstem (in 12 cases) (Fig. 3). Ninety-four of the 100 patients had nonserviceable hearing preoperatively and hence no attempt was made to preserve hearing in these cases. In view of the large tumor size (average size $4.2 \mathrm{~cm}$, range 3-6.6 cm), postoperative facial nerve dysfunction was considered a minor complication, whereas lower cranial nerve dysfunction requiring nasogastric tube placement and CSF leak, meningitis, tumor bed hematoma (whether requiring reoperation or not), and requirement for postoperative tracheostomy and ventilation were considered major complications (9 patients). A contrast-enhanced CT scan was done 1 week after surgery in all patients to determine the extent of tumor removal, and a contrast-enhanced CT scan or MRI study was done at the 1-year follow-up.

\section{Follow-Up Examination}

At the follow-up visits, patients were administered the SF-36 and the GBI. All patients were asked to return for follow-up at 1 year after surgery. While all patients returned for this first full follow-up evaluation (at a mean of $13.5 \pm 5.3$ months postoperatively [range, $9-44$ months]), 51 patients returned for a second follow-up evaluation at a mean of $29.0 \pm 8.3$ months (range 18-50 months) after surgery. QOL data obtained at the first follow-up evaluation (the 1-year evaluation, also referred to as the first follow-
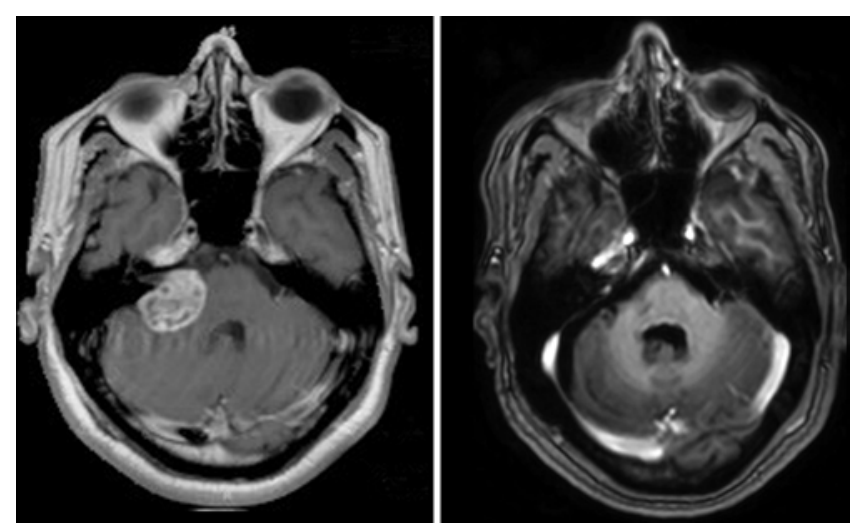

FIG. 1. Left: T1-weighted axial Gd-enhanced MR image obtained in a 53-year-old man showing a 3-cm typical right VS. The patient underwent total excision of the tumor with facial nerve preservation. Right: Follow-up T1-weighted axial Gd-enhanced MR image obtained 3 years after surgery showing no residual tumor. 

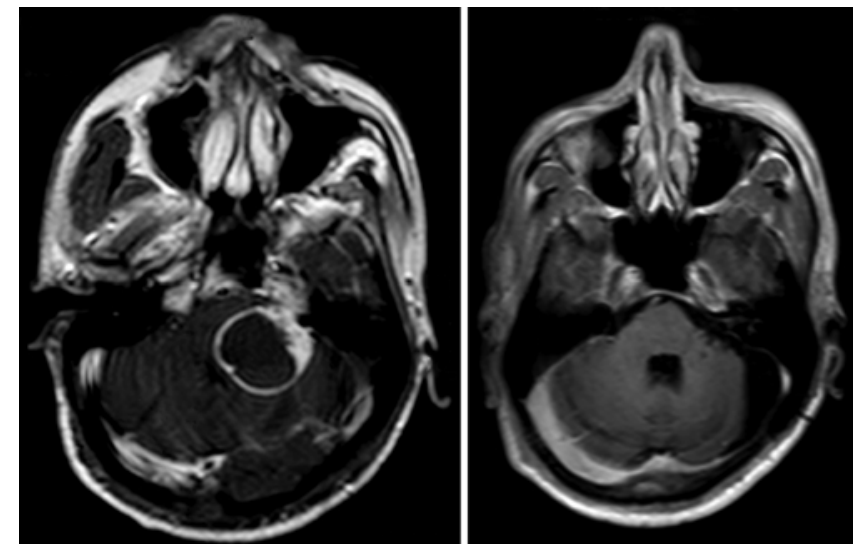

FIG. 2. Left: T1-weighted axial Gd-enhanced MR image obtained in a 47-year-old man showing a 4.2-cm VS with solid and cystic components. The patient underwent total excision of the tumor with facial nerve preservation. Right: Follow-up T1-weighted axial Gd-enhanced MR image obtained 2 years after surgery showing no residual tumor.

up in this paper) were used for analyzing the responsiveness and reliability of the SF-36 and its correlations with various clinical, imaging, and operative features. The data from the second follow-up evaluation $(n=51)$ were used to compare the changes in mean QOL scores over time.

Twelve of the 22 patients who had subtotal excision of their tumors underwent radiosurgery between 9 and 12 months after surgery.

\section{Statistical Analysis}

Data were entered in Microsoft Excel and all statistical analyses were carried out using SPSS Statistics for Windows (Version 17.0., SPSS Inc.).

\section{Analysis of Change in SF-36 Scores}

The percentage of patients with the highest (ceiling) and lowest (floor) possible scores were recorded. Student paired t-tests were used to test for the statistical significance of score changes, and results are presented with 95\% confidence intervals. Differences in changes in total
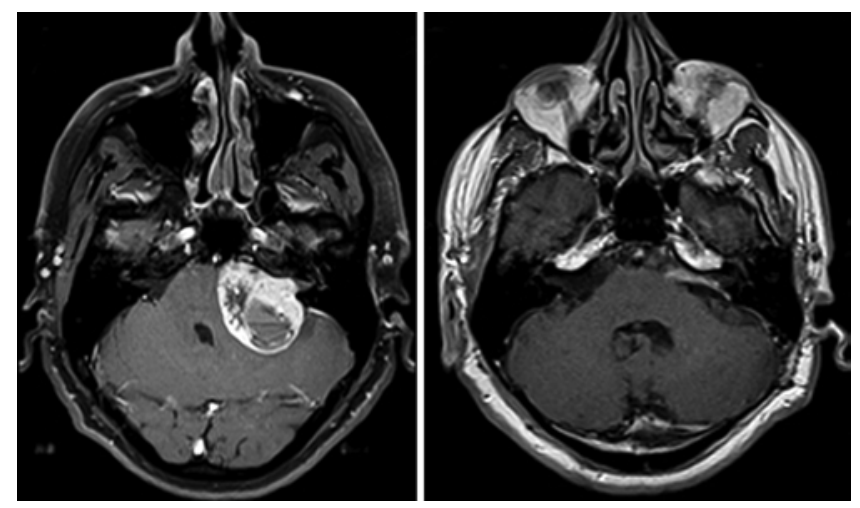

FIG. 3. Left: T1-weighted axial Gd-enhanced MR image obtained in a 57-year-old man showing a 5-cm left VS. The patient underwent subtotal excision of the tumor with facial nerve preservation. Right: Follow-up T1-weighted axial Gd-enhanced MR image obtained 6 months after surgery showing minimal residual tumor just outside the porus on the facial nerve. The patient was followed up without radiosurgery. scores between different subgroups (based on age, size, House-Brackmann grades, postoperative complications, extent of resection, and hydrocephalus) were assessed using the Mann-Whitney U-test.

\section{Responsiveness of the SF-36}

Assessments of responsiveness and change for each domain of the SF-36 were performed using effect sizes, relative efficiency, and MCID. Effect size is defined as the mean change score divided by the SD of the preintervention score. Cohen's benchmarks were used to interpret the magnitude of effect size: $<0.20$, not significant; $0.20-0.49$, small; 0.50-0.79, moderate; and $\geq 0.80$, large. Relative efficiency is calculated as the square of the absolute value t-statistic for each of the domains relative to the domain with the largest t-statistic. It identifies the domain that is most responsive for the intervention.

\section{Reliability of the SF-36}

To determine whether the SF-36 was reliable, we calculated Cronbach's coefficient, alpha, as a measure of internal consistency for each of the multi-item subscales of the SF-36. Experts have recommended 0.7-0.9 as the acceptable range for internal consistency. Further, we used Pearson's correlation coefficient to assess the relationship between the SF-36 summary scores and subscales.

\section{Minimum Clinically Important Difference}

Improvement as measured by the SF-36 was determined based on the calculated values of the MCID, defined as the smallest difference in a questionnaire total or scale/domain score that patients perceive as beneficial (not due to intrinsic variance of the instrument). MCID is based on the standard error of measurement (SEM). The SEM is calculated as the SD of the scores at baseline multiplied by the square root of $(1-r)$, where $r$ is the reliability measure of the scale. We chose " 1 SEM" as a proxy for MCID, as it has been found to correspond with MCID in other studies using the SF-36.

\section{Results}

The clinical and radiological findings, surgical outcomes, and complications are summarized in Table 1. A total of 100 patients were included in this study (65 men and 35 women), and their mean age ( \pm SD) was $44.2 \pm 11.5$ years (range 15-69 years). Their mean preoperative duration of symptoms was $22.1 \pm 26.8$ months (range 1-144 months). The average tumor size was $4.2 \mathrm{~cm}$ (range 3-6.6 $\mathrm{cm})$. Forty-two patients had large tumors $(3-4 \mathrm{~cm}) ; 58 \mathrm{pa}-$ tients had giant tumors $(>4 \mathrm{~cm})$. It is interesting to note that more than $70 \%$ of our patients with large and giant tumors presented with CN V and CN VII involvement and more than $80 \%$ presented with cerebellar ataxia. These deficits could have resulted in a poorer preoperative QOL for these patients compared with the normative population.

\section{Preoperative SF-36 Scores}

The preoperative SF-36 scores of our patients had a wide distribution across various domains, and these scores 
TABLE 1. Presentation, outcome, and complications in 100 patients

\begin{tabular}{|c|c|}
\hline Description & No. of Pts $(\%)$ \\
\hline \multicolumn{2}{|l|}{ Symptoms } \\
\hline Hearing loss & $94(94)$ \\
\hline Tinnitus & $34(34)$ \\
\hline Headache & $57(57)$ \\
\hline Facial numbness & $42(42)$ \\
\hline Facial weakness & $16(16)$ \\
\hline Ataxia & $81(81)$ \\
\hline \multicolumn{2}{|l|}{ Signs } \\
\hline Reduced vision & $13(13)$ \\
\hline Papilledema & $47(47)$ \\
\hline CN V & $79(79)$ \\
\hline CN VI & $3(3)$ \\
\hline CN VII & $77(77)$ \\
\hline CN VIII & $96(96)$ \\
\hline CN IX/X & $12(12)$ \\
\hline Cerebellar signs & $86(86)$ \\
\hline \multicolumn{2}{|l|}{ Radiological findings } \\
\hline Solid tumor & $83(83)$ \\
\hline Cystic tumor & $17(17)$ \\
\hline Hydrocephalus & $20(20)$ \\
\hline \multicolumn{2}{|l|}{ Surgical outcome } \\
\hline Total resection & $78(78)$ \\
\hline Subtotal resection & $22(22)$ \\
\hline Anatomical facial nerve preservation & $85(85)$ \\
\hline Physiological facial nerve preservation & $60(60)$ \\
\hline \multicolumn{2}{|l|}{ Facial nerve function } \\
\hline \multicolumn{2}{|l|}{ HB grade at presentation } \\
\hline I & 22 \\
\hline II & 77 \\
\hline III & 1 \\
\hline IV & 0 \\
\hline $\mathrm{V}$ & 0 \\
\hline \multicolumn{2}{|l|}{ HB grade at discharge } \\
\hline I & 1 \\
\hline II & 12 \\
\hline III & 35 \\
\hline IV & 31 \\
\hline V & 21 \\
\hline \multicolumn{2}{|l|}{ HB grade at follow-up } \\
\hline 1 & 14 \\
\hline II & 20 \\
\hline III & 36 \\
\hline IV & 21 \\
\hline V & 9 \\
\hline
\end{tabular}

TABLE 1. Presentation, outcome, and complications in 100 patients (continued)

\begin{tabular}{lc}
\hline \multicolumn{1}{c}{ Description } & No. of Pts (\%) \\
\hline Complications & $4(4)$ \\
\hline $\begin{array}{l}\text { Discharge on NG tube (removed after varying } \\
\text { intervals) }\end{array}$ & $1(1)$ \\
\hline $\begin{array}{l}\text { Postop tracheostomy (closed before discharge) } \\
\text { Meningitis (treated w/ ABx) }\end{array}$ & $2(2)$ \\
\hline CSF wound leak (subsided w/ lumbar drain) & $3(3)$ \\
\hline CSF rhinorrhea (requiring add'l surgery) & $2(2)$ \\
\hline
\end{tabular}

$\mathrm{ABX}=$ antibiotics; add'l = additional; $\mathrm{HB}=$ House-Brackmann; $\mathrm{NG}=$ nasogastric; pt $=$ patient

were significantly lower in all domains compared with normative scores from the general population (Table 2). For the following SF-36 domains, a sizeable percentage of participants had minimum scores (0): physical role (56\%) and emotional role (64\%). The overall total SF-36 scores were significantly lower in patients older than 45 years but were similar across other subgroups (based on tumor size, patient sex, and presence or absence of hydrocephalus) (Table 3).

\section{Changes in SF-36 Scores at Follow-Up}

Comparison of the average SF-36 scores of the cohort at baseline and the first follow-up evaluation showed an improvement for all domains of the SF-36 (Table 4). Improvements for the participants could be classified as moderate to large for most of the domain scores. More than $60 \%$ of the cohort reached the target MCID in each domain (Table 5). None of variables studied had any correlation with the change in QOL after surgery (Table 6).

Table 7 compares the follow-up SF-36 QOL scores with those for the normative population and at the two follow-ups. At the first follow-up patients' QOL improved to being comparable to the normative population in most domains, but the subscales of physical and emotional role and general health were significantly worse while that of bodily pain was significantly better. Interestingly, at the second follow-up, social functioning and physical role had markedly improved.

The overall internal consistency of the SF-36 was good, ranging from 0.77 to 0.79 .

\section{Glasgow Benefit Inventory Scores}

On the GBI score, $87 \%$ of patients had better total scores, with $1 \%$ showing no change and $12 \%$ reporting deterioration. Table 8 describes changes in postoperative QOL using various subscales of the GBI. There was no significant change in these scales at the second follow-up evaluation.

\section{Discussion}

The SF-36 is a patient-oriented, validated, closed-set, self-assessment questionnaire that has been developed as a general tool for measuring those aspects of health which are important to all individuals and, hence, not dis- 
TABLE 2. SF-36 domain scores and distribution in 100 patients and comparison with normative scores

\begin{tabular}{|c|c|c|c|c|c|}
\hline \multirow[b]{2}{*}{ Domains } & \multirow[b]{2}{*}{ Mean Pt Score (SD) } & \multirow{2}{*}{$\begin{array}{c}\text { No. of Pts w/ } \\
\text { Floor Score (\%) }\end{array}$} & \multirow{2}{*}{$\begin{array}{c}\text { No. of Pts w/ } \\
\text { Ceiling Score }(\%) \dagger\end{array}$} & \multicolumn{2}{|c|}{ Normative Reference Data } \\
\hline & & & & Mean (SD) & p Valuef \\
\hline Physical functioning & $54.44(26.74)$ & $3(3)$ & $3(3)$ & $75.80(24.82)$ & $<0.001$ \\
\hline Physical role & $23.95(34.25)$ & $56(56)$ & $11(11)$ & $73.00(37.44)$ & $<0.001$ \\
\hline Bodily pain & $41.12(26.89)$ & $9(9)$ & $4(4)$ & $60.20(27.47)$ & $<0.001$ \\
\hline General health & $41.94(18.84)$ & $1(1)$ & $0(0)$ & $70.00(19.52)$ & $<0.001$ \\
\hline Vitality & $47.74(18.66)$ & $1(1)$ & $0(0)$ & $65.80(16.87)$ & $<0.001$ \\
\hline Social functioning & $50.16(25.21)$ & $4(4)$ & $7(7)$ & $65.72(23.43)$ & $<0.001$ \\
\hline Emotional role & $22.77(35.73)$ & $64(64)$ & $13(13)$ & $66.68(38.53)$ & $<0.001$ \\
\hline Mental health & $54.35(19.09)$ & $1(1)$ & $0(0)$ & $66.72(15.39)$ & $<0.001$ \\
\hline
\end{tabular}

ease specific. ${ }^{9}$ QOL tools such as the SF-36, as opposed to those specific to VS, help us look beyond the audiofacial morbidity with which VS is commonly associated. Hence, most QOL studies tend to use a generic tool rather than a disease-specific one. The PANQOL (Penn Acoustic Neuroma Quality of Life), a disease-specific scale for VS, has recently been validated (reported in 2010) and could possibly be used as an adjunct to generic tools such as the SF-36. ${ }^{29}$

\section{Preoperative QOL in Patients With VS}

The SF-36 scores of VS patients at diagnosis were significantly lower compared not only with scores of healthy controls, but also with those of patients with head and neck cancer, benign prostate hypertrophy, or chronic obstructive pulmonary disease and deaf patients. ${ }^{32}$ Di Maio and Akagami, ${ }^{8}$ in a prospective study, observed worse QOL in patients with tumors larger than $3 \mathrm{~cm}$ than in those with smaller tumors. Patients with larger tumors, which cause brainstem compression and hydrocephalus, understandably have a poorer quality of life compared with patients harboring smaller tumors. We also noted significantly lower QOL in our patients with large and giant VSs.

TABLE 3. Effect of different features on SF-36 scores

\begin{tabular}{lccc}
\hline \multicolumn{1}{c}{ Features } & No. of Pts & $\begin{array}{c}\text { Mean Total QOL } \\
\text { Score (SD) }\end{array}$ & p Value* \\
\hline Tumor size & & & 0.30 \\
\hline$\quad$ 4 cm (mean 36.2 mm) & 42 & $44.45(16.51)$ & \\
\hline$>4 \mathrm{~cm}($ mean $48.4 \mathrm{~mm})$ & 58 & $40.84(18.06)$ & \\
\hline Sex & & & 0.95 \\
\hline$\quad$ Male & 65 & $42.45(18.28)$ & \\
\hline Female & 35 & $42.20(16.00)$ & \\
\hline Age & & & 0.04 \\
\hline$\quad$ 45 yrs & 54 & $45.61(18.07)$ & \\
\hline$\quad>45$ yrs & 46 & $38.54(16.02)$ & \\
\hline Hydrocephalus & & & 0.06 \\
\hline$\quad$ No & 80 & $43.97(16.93)$ & \\
\hline Yes & 20 & $35.90(18.37)$ & \\
\hline
\end{tabular}

* Bold type indicates statistical significance.
Thus, it is prudent to use each patient as his or her own control to determine QOL outcome after surgery. If the normative population scores are used to determine the outcome of surgery for large and giant VS, the benefits of surgery will be underestimated.

\section{Improvement in QOL After Surgery}

In 1995, Irving et al. ${ }^{13}$ reported, after retrospectively analyzing questionnaires sent to 227 patients, that QOL was excellent after VS surgery. The validity of these results was questioned because of the study design and QOL instrument used (a modified European Organization for Research and Treatment of Cancer [EORTC] QLQ-C30 questionnaire used for cancer patients). Studies of this type are difficult to interpret without baseline values and normalized population standards for QOL comparison. Di Maio and Akagami ${ }^{8}$ demonstrated for the first time a clinically significant improvement in QOL scores in patients with VSs larger than $3 \mathrm{~cm}$ as early as 1.5 months following surgery and through a 2-year follow-up. They also evaluated patients who were conservatively managed or underwent radiotherapy for smaller tumors. While they found no baseline difference in QOL among these 3 groups, QOL remained unchanged for the observation and radiotherapy group throughout the follow-up period. However, there was a significant improvement in those who underwent surgery for smaller tumors as well as the larger ones. In a retrospective study comparing postoperative QOL with QOL in the normal healthy Australian population, Cheng et al., ${ }^{6}$ showed that following surgery patients reported a QOL nearly equivalent to the healthy population in all domains except for that of physical role limitation.

Many other retrospective studies have demonstrated a postoperative decline in QOL-either in total scores or in the majority of subscale scores. ${ }^{2,37,19,22,31}$ Our findings and those of Sandooram et al. ${ }^{26}$ and Di Miao et al. ${ }^{8}$ are at some variance with the findings of these studies. However, it must be pointed out that in our study we compared the QOL at follow-up with preoperative QOL, whereas in the retrospective studies, the only comparison possible was with values obtained in the general population. As explained above, patients with large VSs might not regain 
TABLE 4. Changes in SF-36 domain scores at first follow-up

\begin{tabular}{lllcccccc}
\hline \multicolumn{1}{c}{ Domains } & Preop Mean & $\begin{array}{c}\text { 1st Follow-Up } \\
\text { Mean }\end{array}$ & Mean Change & $\begin{array}{c}\text { 95\% Cl for } \\
\text { Mean Change }\end{array}$ & ES & t-Value* $(\mathrm{p}$ value) & MCID & RE \\
\hline Physical functioning & $54.4(26.7)$ & $69.6(24.6)$ & $15.2(31.2)$ & $9-21.37$ & 0.56 & $4.85(<0.001)$ & 10.3 & 0.54 \\
\hline Physical role & $24(34.3)$ & $48.5(38.7)$ & $24.5(44.1)$ & $15.8-33.3$ & 0.71 & $5.55(<0.001)$ & 13 & 0.62 \\
\hline Bodily pain & $41.1(26.9)$ & $68.3(23.3)$ & $27.2(30.8)$ & $21.1-33.3$ & 1.01 & $8.84(<0.001)$ & 10.2 & 1.00 \\
\hline General health & $41.9(18.8)$ & $63(21.6)$ & $21(26.4)$ & $15.8-26.3$ & 1.11 & $7.95(<0.001)$ & 7.14 & 0.89 \\
\hline Vitality & $47.7(18.7)$ & $61(18.9)$ & $13.3(25.1)$ & $8.3-18.3$ & 0.70 & $5.27(<0.001)$ & 7.06 & 0.59 \\
\hline Social functioning & $50.2(25.2)$ & $70.6(24.7)$ & $20.5(32.9)$ & $14-27$ & 0.80 & $6.22(<0.001)$ & 9.57 & 0.70 \\
\hline Emotional role & $22.8(35.7)$ & $54.8(43)$ & $32(47.4)$ & $22.6-41.4$ & 0.89 & $6.75(<0.001)$ & 13.56 & 0.76 \\
\hline Mental health & $54.4(19.1)$ & $68.7(19.6)$ & $14.3(24.6)$ & $9.5-19.2$ & 0.75 & $5.82(<0.001)$ & 7.22 & 0.65 \\
\hline Total score & $42.4(17.4)$ & $63.2(19.1)$ & $20.8(21.0)$ & $16.6-25$ & 1.19 & $9.89(<0.001)$ &
\end{tabular}

$E S=$ effect size; $R E=$ relative efficiency.

* From paired t-test.

"normal" QOL in all domains but do improve from their preoperative functional status.

Using the GBI, various authors have reported that only $17 \%-30 \%$ of patients considered their condition to be "better" after surgery for VS while up to $56 \%$ of patients felt they it was "worse.", $1,21,23$ Using the GBI, Nikolopoulos et al..$^{23}$ categorized surgically treated VS patients' response to the GBI by the percentage of replies of "better" (17\%), "unchanged" (29\%), or "worse" (54\%). Analyzed similarly, the replies obtained by Myrseth et $\mathrm{al}^{21}$ were in the same range $(18 \%, 42 \%$, and $39 \%$, respectively). The corresponding results obtained by Alfonso et al. ${ }^{1}$ were $30 \%$, $14 \%$ and $56 \%$. In contrast to these findings, $87 \%$ of our patients reported feeling "better," and only $12 \%$ patients reported deterioration after surgery.

This discrepancy could be explained partly on the basis of cultural differences but also could reflect differences in individual expectations for surgical outcome. While some patients might consider regaining employment a giant leap in their perceived QOL, others may be distraught over a slight facial paralysis after surgery. Therefore, counseling of patients prior to surgery with truthful presentation of realistic goals and possible results of surgery may lead to better acceptance of surgical outcomes.

\section{Clinically Significant Change in QOL}

The concept of minimum clinically significant difference (MCID) has been a valuable advance in HR-QOL research. MCID is defined as the smallest difference in

TABLE 5. Number of patients who achieved the estimated MCID in each domain of QOL

\begin{tabular}{lcc}
\hline \multicolumn{1}{c}{ Domain } & Estimated MCID & No. of Pts (\%) \\
\hline Physical functioning & 10.34 & $73(73)$ \\
\hline Physical role & 12.99 & $68(68)$ \\
\hline Bodily pain & 10.18 & $77(77)$ \\
\hline General health & 7.14 & $81(81)$ \\
\hline Vitality & 7.06 & $79(79)$ \\
\hline Social functioning & 9.57 & $84(84)$ \\
\hline Emotional role & 13.56 & $63(63)$ \\
\hline Mental health & 7.22 & $74(74)$ \\
\hline
\end{tabular}

score on an HR-QOL instrument that patients perceive as beneficial and that would mandate, in the absence of troublesome side effects and excessive cost, a change in the patient's management. The MCID values in our study varied from 7.06 to 13.56 in various domains, with $63 \%-84 \%$ of the patients having achieved the target values at follow-up assessment in all the domains of the SF-36 (Table 5). Improvements for our participants could be classified as large (effect size $\geq 0.80$ ) for all domains except for the physical functioning and physical role scores. The bodily pain domain of the SF-36 was most sensitive to change (largest t-value) and was considered as a reference to calculate the relative efficiency. The general health, mental health, social functioning, and emotional role domains were quite sensitive to change relative to the bodily pain component of the SF-36. Physical functioning, physical role, and vitality demonstrated moderate-to-small sensitivity to change (Table 4).

\section{Factors Affecting QOL in Patients With VS}

Age and Sex

Tufarelli et al. ${ }^{31}$ showed that younger patients fared

TABLE 6. Effect of prognostic factors on change in QOL

\begin{tabular}{lccc}
\hline \multicolumn{1}{c}{ Features } & No. of Pts & $\begin{array}{c}\text { Mean Change in } \\
\text { Total QOL (SD) }\end{array}$ & p Value \\
\hline HB grade* & & & 0.87 \\
\hline IV \& V & 30 & $20.50(19.86)$ & \\
\hline I-III & 70 & $20.92(21.64)$ & \\
\hline Operative complications & & & 0.09 \\
\hline Yes & 9 & $11.44(17.16)$ & \\
\hline No & 91 & $21.72(21.22)$ & \\
\hline Excision & & & \\
\hline Total & 78 & $21.30(20.09)$ & \\
\hline$\quad$ Partial & 22 & $19.00(24.47)$ & \\
\hline Hydrocephalus $\dagger$ & & & \\
\hline$\quad$ No (ratio <40\%) & 80 & $20.57(21.58)$ & \\
\hline Yes (ratio $\geq 40 \%)$ & 20 & $21.70(19.13)$ & \\
\hline * At follow-up. & & \\
$\dagger$ At presentation. & &
\end{tabular}


TABLE 7. Comparison of serial follow-up QOL scores with normative scores and with each other

\begin{tabular}{|c|c|c|c|c|c|c|}
\hline \multirow[b]{2}{*}{ Domain } & \multicolumn{3}{|c|}{ QOL Score* } & \multicolumn{3}{|c|}{$p$ Value } \\
\hline & Normative & $\begin{array}{l}\text { 1st Follow-Up } \\
(n=100)\end{array}$ & $\begin{array}{l}\text { 2nd Follow-Up } \\
\qquad(n=51)\end{array}$ & $\begin{array}{l}\text { Normative vs 1st } \\
\text { Follow-Up }\end{array}$ & $\begin{array}{l}\text { Normative vs } 2 \text { nd } \\
\quad \text { Follow-Up }\end{array}$ & $\begin{array}{l}\text { 1st vs 2nd } \\
\text { Follow-Up }\end{array}$ \\
\hline Physical functioning & $75.80(24.82)$ & $69.62(24.58)$ & 77.06 (19.97) & 0.07 & 0.75 & 0.06 \\
\hline Physical role & $73.00(37.44)$ & $48.46(38.70)$ & $64.22(37.50)$ & $<0.001$ & 0.17 & 0.01 \\
\hline Bodily pain & $60.20(27.47)$ & $68.33(23.34)$ & $71.94(23.21)$ & 0.02 & 0.008 & 0.36 \\
\hline General health & 70.00 (19.52) & $62.95(21.59)$ & $63.51(21.01)$ & 0.01 & 0.06 & 0.87 \\
\hline Vitality & $65.80(16.87)$ & 61.01 (18.92) & $64.10(20.59)$ & 0.06 & 0.58 & 0.35 \\
\hline Social functioning & $65.72(23.43)$ & $70.64(24.66)$ & $79.82(23.81)$ & 0.14 & $<0.001$ & 0.03 \\
\hline Emotional role & $66.68(38.53)$ & $54.77(42.95)$ & $68.47(37.43)$ & 0.04 & 0.78 & 0.05 \\
\hline Mental health & 66.72 (15.39) & 68.68 (19.64) & 72.55 (22.05) & 0.43 & 0.06 & 0.27 \\
\hline
\end{tabular}

* Scores are given as means (SD).

† Bold type indicates statistical significance.

better than older patients. We, too, found higher scores in patients younger than 45 years. On the other hand, Nikolopoulos et al. ${ }^{23}$ found, using the GBI questionnaire, that the mean age at operation in patients who reported a better postoperative QOL was significantly higher (57.6 years) than in patients who reported the same or worse postoperative QOL (47.2 years). In other studies age had no effect on QOL. 1,6,13,26 Similarly, while some reports showed women to have lower scores than men, ${ }^{2,14,19,20,22,31}$ other studies, including our own, showed no difference in SF-36 scores between male and female patients. ${ }^{1,6,7}$

\section{Tumor Size}

Several authors have reported no effect of tumor size on QOL scores. ${ }^{1,6,7,23}$ However, others have reported a worse QOL in patients with larger tumors..$^{13,19,22,31}$ In our cohort there was no difference in the QOL score between patients harboring large tumors $(3-4 \mathrm{~cm})$ and those harboring gi-

TABLE 8. Postoperative $Q O L$ assessed using various domains of the $\mathrm{GBI}{ }^{*}$

\begin{tabular}{cccc}
\hline GBI & $\begin{array}{c}\text { 1st Follow-Up } \\
(\mathrm{n}=100)\end{array}$ & $\begin{array}{c}\text { 2nd Follow-Up } \\
(\mathrm{n}=51)\end{array}$ & p Value \\
\hline Total score & & & \\
\hline Worse & $12(12)$ & $4(7.8)$ & 0.42 \\
\hline No change & $1(1)$ & $2(3.9)$ & 0.22 \\
\hline Improved & $87(87)$ & $45(88.2)$ & 0.83 \\
\hline Subscale, general & & & \\
\hline Worse & $20(20)$ & $8(15.7)$ & 0.051 \\
\hline No change & $5(5)$ & $1(2)$ & 0.36 \\
\hline Improved & $75(75)$ & $42(82.4)$ & 0.30 \\
\hline Social subscale & & & \\
\hline Worse & $5(5)$ & $5(9.8)$ & 0.26 \\
\hline No change & $10(10)$ & $5(9.8)$ & 0.96 \\
\hline Improved & $85(85)$ & $41(80.4)$ & 0.47 \\
\hline Physical subscale & & & \\
\hline Worse & $20(20)$ & $8(15.7)$ & 0.51 \\
\hline No change & $11(11)$ & $3(5.9)$ & 0.30 \\
\hline Improved & $69(69)$ & $40(78.4)$ & 0.22 \\
\hline
\end{tabular}

* Values in parentheses are percentage of patients. ant tumors ( $>4 \mathrm{~cm})$, but since all of the patients enrolled in this study had tumors that were at least $3 \mathrm{~cm}$ in diameter, this result is not surprising.

\section{Facial Function}

The impact of postoperative facial nerve function on patients' QOL remains controversial. While some authors suggest that facial paresis has a significant bearing on postoperative QOL, 4,17,22 others found no difference in QOL between patients with and without facial nerve dysfunction, or between those with different grades of facial nerve function..$^{15,16,25}$ Schwartz et al. ${ }^{28}$ have noted no significant difference in QOL between patients with good versus poor facial nerve function. They proposed that since patients with poor facial nerve function had larger tumors, they may have been more able to reconcile their facial weakness, without perceiving it as a major QOL problem. Other groups have similarly demonstrated that facial weakness is overestimated by surgeons as a primary determinant of QOL.8,16,21

In our study we did not find a change in total postoperative QOL scores in patients with good versus poor facial function. However, when we looked at individual domains, patients in the latter group had expectedly lower scores on the social subscale.

\section{Other Factors}

Studies have reported postoperative hearing loss, tinnitus, vertigo, and balance problems as having an impact on QOL, complications which mainly affect the patients' social functioning and return to work. ${ }^{4,5,19,27}$ We found a trend toward a lower change in QOL in patients who had a postoperative complication, but this was not statistically significant $(\mathrm{p}=0.09)$.

\section{Changes in QOL With Time}

In one of the two prospectively conducted trials, Pollock et al. ${ }^{24}$ showed using the Health Status Questionnaire scores (modification of the SF-36) that there was persistent worsening of QOL even beyond 1 year after surgery. On the other hand, Sandooram et al. ${ }^{26}$ showed that while the SF-36 scores were significantly reduced at 1 month after surgery, by 3 months after microsurgery the scores had reached the preoperative levels. 
Di Maio and Akagami ${ }^{8}$ showed clinically significant improvement in QOL as early as 1.5 months after surgery and through 2 years' follow-up in patients who underwent resection of VSs larger than $3 \mathrm{~cm}$. This improvement was seen both on the SF-36 scales and on the GBI scale, a result that contradicts findings from previous studies.

We found that at 1 year after surgery QOL had improved to the level of the normative population in most domains. The scores on the subscales of physical and emotional role and general health were significantly worse but the scores for bodily pain were significantly better than those of the normative population. Interestingly, with additional follow-up, we found not only sustainable scores in all domains but also statistically significant improvements in the physical role $(\mathrm{p}=0.01)$ and social functioning $(\mathrm{p}=$ 0.03 ) scores compared with scores from the 1-year followup evaluation.

\section{Limitations}

Since QOL is essentially determined by the patient, data cannot be generated from patients who die postoperatively or whose mental status prevents comprehension of the QOL instrument. Due to this constraint, we could not include data from 3 patients (2 died, 1 discharged moribund) for whom postoperative SF-36 scores were not possible to obtain. As a counterbalance to the possible overreporting of good outcomes, we were also not able to include 2 patients who presented in altered sensorium and returned home well after excision of a giant VS, since the patients were unable to provide the QOL prior to surgery.

Cultural aspects and socioeconomic status affect QOL, and the findings of one cohort may be at variance with those of another. This study is thus far the largest series in the literature, and further prospectively conducted studies from other cultural cohorts might provide valuable insight into the QOL of patients undergoing surgery for large and giant VSs.

\section{Conclusions}

Before surgery, patients harboring large or giant VSs score lower than the normative population on all the SF-36 domains. A majority of patients $(>60 \%)$ showed a clinically significant improvement (MCID) in QOL 1 year after surgery. Older patients ( $>45$ years) had worse QOL, but facial nerve function and tumor size had no bearing on QOL. For some of the SF-36 domains, patients demonstrated significant improvement on serial postoperative QOL assessments.

\section{References}

1. Alfonso C, Lassaletta L, Sarriá J, Gavilán J: [Quality of life following vestibular schwannoma surgery.] Acta Otorrinolaringol Esp 58:61-65, 2007 (Span)

2. Barré P, Merle C, Conessa C, Desgeorges M, Poncet JL: [Postoperative quality of life for patients with a vestibular schwannoma.] Ann Otolaryngol Chir Cervicofac 121:8394, 2004 (Fr)

3. Baumann I, Polligkeit J, Blumenstock G, Mauz PS, Zalaman IM, Maassen MM: Quality of life after unilateral acoustic neuroma surgery via middle cranial fossa approach. Acta Otolaryngol 125:585-591, 2005
4. Betchen SA, Walsh J, Post KD: Self-assessed quality of life after acoustic neuroma surgery. J Neurosurg 99:818-823, 2003

5. Browne S, Distel E, Morton RP, Petrie KJ: Patients' quality of life, reported difficulties, and benefits following surgery for acoustic neuroma. J Otolaryngol Head Neck Surg 37:417-422, 2008

6. Cheng S, Naidoo Y, da Cruz M, Dexter M: Quality of life in postoperative vestibular schwannoma patients. Laryngoscope 119:2252-2257, 2009

7. da Cruz MJ, Moffat DA, Hardy DG: Postoperative quality of life in vestibular schwannoma patients measured by the SF36 Health Questionnaire. Laryngoscope 110:151-155, 2000

8. Di Maio S, Akagami R: Prospective comparison of quality of life before and after observation, radiation, or surgery for vestibular schwannomas. J Neurosurg 111:855-862, 2009

9. Garratt AM, Ruta DA, Abdalla MI, Buckingham JK, Russell IT: The SF36 health survey questionnaire: an outcome measure suitable for routine use within the NHS? BMJ 306:1440-1444, 1993

10. Gauden A, Weir P, Hawthorne G, Kaye A: Systematic review of quality of life in the management of vestibular schwannoma. J Clin Neurosci 18:1573-1584, 2011

11. Gouveris HT, Mann WJ: Quality of life in sporadic vestibular schwannoma: a review. ORL J Otorhinolaryngol Relat Spec 72:69-74, 2010

12. House JW, Brackmann DE: Facial nerve grading system. Otolaryngol Head Neck Surg 93:146-147, 1985

13. Irving RM, Beynon GJ, Viani L, Hardy DG, Baguley DM, Moffat DA: The patient's perspective after vestibular schwannoma removal: quality of life and implications for management. Am J Otol 16:331-337, 1995

14. Iyer AP, Gunn R, Sillars H: Quality of life after vestibular schwannoma surgery: does hearing preservation make a difference? J Laryngol Otol 124:370-373, 2010

15. Kelleher MO, Fernandes MF, Sim DW, O'Sullivan MG: Health-related quality of life in patients with skull base tumours. Br J Neurosurg 16:16-20, 2002

16. Lassaletta L, Alfonso C, Del Rio L, Roda JM, Gavilan J: Impact of facial dysfunction on quality of life after vestibular schwannoma surgery. Ann Otol Rhinol Laryngol 115:694698, 2006

17. Lee J, Fung K, Lownie SP, Parnes LS: Assessing impairment and disability of facial paralysis in patients with vestibular schwannoma. Arch Otolaryngol Head Neck Surg 133:5660, 2007

18. Magliulo G, Zardo F, Damico R, Varacalli S, Forino M: Acoustic neuroma: postoperative quality of life. J Otolaryngol 29:344-347, 2000

19. Martin HC, Sethi J, Lang D, Neil-Dwyer G, Lutman ME, Yardley L: Patient-assessed outcomes after excision of acoustic neuroma: postoperative symptoms and quality of life. $\mathbf{J}$ Neurosurg 94:211-216, 2001

20. Myrseth E, Møller P, Pedersen PH, Lund-Johansen M: Vestibular schwannoma: surgery or gamma knife radiosurgery? A prospective, nonrandomized study. Neurosurgery 64:654-663, 2009

21. Myrseth E, Møller P, Pedersen PH, Vassbotn FS, WentzelLarsen T, Lund-Johansen M: Vestibular schwannomas: clinical results and quality of life after microsurgery or gamma knife radiosurgery. Neurosurgery 56:927-935, 2005

22. Nicoucar K, Momjian S, Vader JP, de Tribolet N: Surgery for large vestibular schwannomas: how patients and surgeons perceive quality of life. J Neurosurg 105:205-212, 2006

23. Nikolopoulos TP, Johnson I, O’Donoghue GM: Quality of life after acoustic neuroma surgery. Laryngoscope 108:1382-1385, 1998

24. Pollock BE, Driscoll CL, Foote RL, Link MJ, Gorman DA, Bauch CD, et al: Patient outcomes after vestibular schwan- 
noma management: a prospective comparison of microsurgical resection and stereotactic radiosurgery. Neurosurgery 59:77-85, 2006

25. Rameh C, Magnan J: Quality of life of patients following stages III-IV vestibular schwannoma surgery using the retrosigmoid and translabyrinthine approaches. Auris Nasus Larynx 37:546-552, 2010

26. Sandooram D, Grunfeld EA, McKinney C, Gleeson MJ: Quality of life following microsurgery, radiosurgery and conservative management for unilateral vestibular schwannoma. Clin Otolaryngol Allied Sci 29:621-627, 2004

27. Scheich M, Ginzkey C, Reuter E, Harnisch W, Ehrmann D, Hagen R: Quality of life after microsurgery for vestibular schwannoma via the middle cranial fossa approach. Eur Arch Otorhinolaryngol 271:1909-1916, 2014

28. Schwartz MS, Riddle SA, Delashaw JB Jr, Horgan MA, Kel$\operatorname{logg}$ JX, McMenomey SO: Quality of life following acoustic neuroma surgery. Neurosurg Focus 5(3):E3, 1998

29. Shaffer BT, Cohen MS, Bigelow DC, Ruckenstein MJ: Validation of a disease-specific quality-of-life instrument for acoustic neuroma: the Penn Acoustic Neuroma Quality-ofLife Scale. Laryngoscope 120:1646-1654, 2010

30. Thakar S, Christopher S, Rajshekhar V: Quality of life assessment after central corpectomy for cervical spondylotic myelopathy: comparative evaluation of the 36-Item Short Form Health Survey and the World Health Organization Quality of Life-Bref. J Neurosurg Spine 11:402-412, 2009

31. Tufarelli D, Meli A, Alesii A, De Angelis E, Badaracco C,
Falcioni M, et al: Quality of life after acoustic neuroma surgery. Otol Neurotol 27:403-409, 2006

32. Vogel JJ, Godefroy WP, van der Mey AG, le Cessie S, Kaptein AA: Illness perceptions, coping, and quality of life in vestibular schwannoma patients at diagnosis. Otol Neurotol 29:839-845, 2008

\section{Author Contributions}

Conception and design: Rajshekhar. Acquisition of data: Turel. Analysis and interpretation of data: all authors. Drafting the article: Rajshekhar, Turel. Reviewed submitted version of manuscript: all authors. Approved the final version of the manuscript on behalf of all authors: Rajshekhar. Statistical analysis: Thakar.

\section{Supplemental Information}

Previous Presentation

Portions of this work were presented as a platform presentation at the 60th Annual Conference of the Neurological Society of India in Bangalore, December 2011.

\section{Correspondence}

Vedantam Rajshekhar, Department of Neurological Sciences, Christian Medical College, Vellore 632 004, India. email: rajshekhar@cmcvellore.ac.in. 